\title{
CARTOGRAFIANDO DIVERSIDADES RELIGIOSAS. UN PRIMER ACERCAMIENTO A LAS PERIFERIAS DE LA CIUDAD DE LUJÁN (BUENOS AIRES, ARGENTINA)
}

- MARCOS BRUNO GIOP ${ }^{1}$

Profesor en Geografía (Universidad Nacional de Luján, Argentina). Estudiante de la Licenciatura en Geografía (UNLu). Miembro del GIEPEC. Ex becario CIN EVC (dos períodos). Docente Auxiliar Ordinario del Departamento de Ciencias Sociales de la Universidad Nacional de Luján (Argentina). E-mail para contato: rmarcobg14@hotmail.com.

Recebido em: 14/06/2020

Aprovado em: 2008/2020

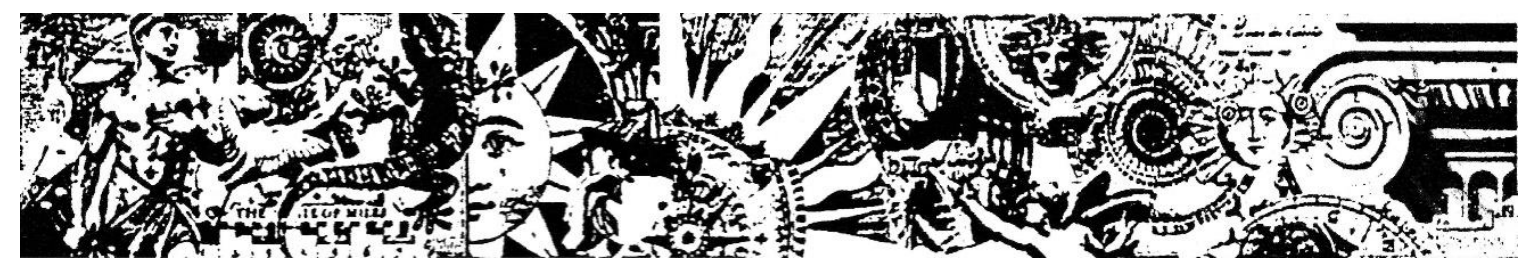

Resumen: La dimensión religiosa es uno de las principales cohesionadares espaciales de la ciudad de Luján (pravincia de Buenos Aires, Argentina). La urbe es el centra católica mariano par excelencia de la Argentina; todas los años recibe un gran flujo de visitantes los cuales acuden a diferentes peregrinaciones y eventos vinculados, en mayor a menor medida, a lo sagrado. En una primera instancia de trabajo nos propusimos una labor exploratoria que diera cuenta de la diversidad religiosa expresada espacialmente en la zona céntrica de la urbe. A partir de las experiencias acumuladas, quedá la tarea pendiente de extender el área de estudio hacia las zonas más periféricas de la ciudad. Así, aunque con metodalogías diferentes, nas proponemos mastrar algunas resultados de esta nueva etapa de trabajo. La investigación, en este casa, se concentró de manera específica en la categoría de los templos para mastrar cómo estas materialidades san una expresión de la diversidad religiosa en el espacio público. Como principal fuente de información (aunque no excluyente) se trabajó con el Registro Nacional de Cultas, complementado con el trabajo de campo y la elaboración de cartografía temática.

Palavras-Clave: Pluralidad religiosa, espacio público, geosímbolos, territorialidad. 


\section{MAPPING RELIGIOUS DIVERSITIES. A FIRST APPRDACH TQ THE FRINGES OF LUJÁN'S CITY (BLENDS AIRES, ARGENTINA)}

ABSTRACT: THE RELIGIOUS DIMENSIINN IS UNE DF THE MAIN SPATIAL CDHESIONISTS OF THE CITY OF LUJÁN (PRDVINCE DF BUENDS AIRES). THE CITY IS THE QUINTESSENTIAL MARIAN CATHOLIC CENTER OF ARGENTINA; EVERY YEAR IT RECEIVES A GREAT FLOW UF VISITORS WHO GO TQ DIFFERENT PILGRIMAGES AND EVENTS LINKED, TQ A GREATER OR LESSER EXTENT, TQ THE SACRED. IN THE FIRST INSTANCE OF WORK, WE PROPOSED AN EXPLORATORY WORK THAT WOULD ACCDUNT FOR THE RELIGIOUS DIVERSITY EXPRESSED SPATIALLY IN THE DOWNTOWN AREA DF THE CITY. FROM THE ACEUMULATED EXPERIENCES, THE PENDING TASK DF EXTENDING THE STUDY AREA TO THE MDST PERIPHERAL AREAS OF THE CITY REMAINED. THUS, ALTHDUGH WITH DIFFERENT METHODOLDGIES, WE PROPUSE TO SHOW SDME RESULTS OF THIS NEW STAGE OF WORK.

THE RESEARCH, IN THIS CASE, FOCUSED SPECIFICALLY IN THE CATEGORY DF TEMPLES TO SHOW HOW THESE MATERIALITIES ARE AN EXPRESSION UF RELIGIOUS DIVERSITY IN PUBLIC SPACE.

AS THE MAIN SOURCE OF INFORMATION, (ALTHDUGH NDT EXCLUSIVE) WE WORKED WITH THE NATIONAL REGISTRY OF WORSHIP, CDMPLEMENTED BY FIELD WORK AND THE DEVELIPMMENT DF THEMATIC CARTOGRAPHY.

KEYWDRDS: RELIIIDUS PLURALITY, PUBLIC SPACE, GEOSYMBOLS, TERRITORIALITY.

\section{MAPEANDO DIVERSIDADES RELIGIDSAS. UMA PRIMEIRA ABDRDAGEM PARA AS PERIFERIAS DA CIDADE DA LUJÁN (BLENGS AIRES, ARGENTINA)}

RESUMD: A DIMENSÃ̃ RELIGIISA É UM DIS PRINCIPAIS CDESIONISTAS ESPACIAIS DA CIDADE DE LUJÁN (PRDVÍNCIA DE BULNDS AIRES). A CIDADE É Q CENTRQ CATÓLICD MARIAND PDR EXCELÊNCIA DA ARGENTINA; A CADA AND RECEBE UM GRANDE FLUXD DE VISITANTES QUE VÃ̃ A DIFERENTES PEREGRINAÇ̃̃ES E EVENTUS LIGADUS, EM MAIIR OU MENDR GRAU, AD SAGRADU.

NA PRIMEIRA INSTÂNCIA DO TRABALHD, PROPUSEMUS UM TRABALHO EXPLDRAT́́RII QUE EXPLICARIA A DIVERSIDADE RELIIIOSA EXPRESSA ESPACIALMENTE ND CENTRD DA CIDADE. A PARTIR DAS EXPERIÊNCIAS ACLMULLADAS, PERMANECEU A TAREFA PENDENTE DE ESTENDER A ÁREA DE ESTUDD PARA AS ÁREAS MAIS PERIFÉRICAS DA CIDADE. ASSIM, EMBDRA CDM DIFERENTES METODOLOGIAS, PROPOMUS MUSTRAR ALGUNS RESULTADOS DESSA NDVA ETAPA DO TRABALHD.

A PESDUISA, NESSE CASD, CDNCENTRDU-SE ESPECIFICAMENTE NA CATEGURIA DE TEMPLIS PARA MDSTRAR CDMU ESSAS MATERIALIDADES SÃ̃ UMA EXPRESSÃ̃ DA DIVERSIDADE RELIGIOSA ND ESPAÇ口 PÍBLICD.

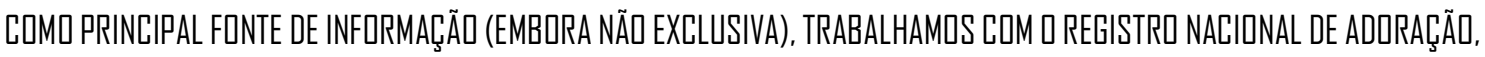
CDMPLEMENTADO POR TRABALHO DE CAMPO E DESENVDLVIMENTO DE CARTOGRAFIA TEMÁTICA.

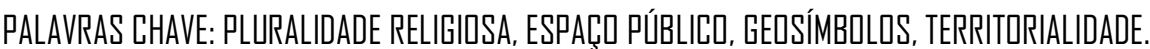

\section{Lo urbano y lo religioso: el constructivismo geográfico}

Desde Según Alicia Lindón (2007) existió (y aún persiste) una clara tendencia a estudiar las ciudades desde una perspectiva "a vuelo de pájaro". De esta manera, la visión de la ciudad (y el foco desde donde se produce la investigación y el análisis) se suele realizar por "encima" de la misma, y, en muchos casos, se termina abordando a la urbe y sus producciones espaciales, pero ignorando a los sujetos que la producen día 
a día. Otra crítica que realiza la geógrafa cultural va en sintonía con la idea de pensar al espacio como un mero producto social, poniendo énfasis únicamente en sus componentes materiales y dejando de lado el universo de lo inmaterial y lo simbólico.

Por estas cuestiones es que, a partir de ideas tomadas del constructivismo geográfico, se comienza a pensar en un "quehacer geográfico", partiendo de las experiencias de los sujetos que en su habitar cotidiano son quienes construyen la espacialidad de la ciudad. El constructivismo geográfico sería entonces, un conjunto de prácticas donde el sujeto habitante construye los lugares día a día y estos (los lugares) configuran las identidades de los sujetos que lo habitan (LINDÓN, 2008).

Deben subrayarse dos aspectos de estos modos de entender "lo urbano". Por un lado, la importancia de pensar que la espacialidad se va configurando de manera inacabada en esta relación bidireccional sujeto(s) - lugar(es), donde ambos se influyen uno al otro; y por el otro, la recuperación del concepto de lugar, pensando en una espacialidad relativa y cuestionando la visión de un espacio in situ.

Es fundamental pensar a la ciudad desde un enfoque donde se ponga el punto de atención en los componentes inmateriales y simbólicos que se van generando de manera constante por parte de los sujetos que la producen en el día a día. Como sostenía Bailly (1989) es necesario tener en cuenta que la espacialidad de la vida social no debería reducirse a una realidad material única y externa a las personas, sino que debe sumarlas e involucrarlas.

Sin embargo, mitigar la influencia de las perspectivas materialistas y que se enfocan en lo macro, no significa invisibilizarlas; por el contrario, se insiste en incorporarlas a este nuevo universo y verlas como un todo constitutivo, lejos de ser armonioso.

La ciudad se va construyendo diariamente a través de los imaginarios urbanos (Lindón, 2007). Estos son procesos donde los sujetos a través de sus prácticas van conformando los paisajes de las ciudades. Es muy importante entender que los sujetoshabitantes a través de su experiencia cotidiana espacial (en un juego simbólico y recíproco de subjetividad e intersubjetividad) son uno de los principales constructores de los espacios urbanos en lo cotidiano.

El estudio geográfico de lo urbano posee, entonces, un importante recorrido desde la consolidación de la ciencia en la segunda mitad del siglo XIX; sin embargo, no ocurre lo mismo con el estudio espacial de lo religioso. 
El gran punto de inflexión en los estudios sobre geografía de la religión, según Fernandez Christlieb (2006) se produjo a partir de la incorporación de abordajes culturales. Si bien a lo largo del siglo XX hubo aportes desde una Geografía Cultural, sobre todo impulsada a partir de la Escuela de Berkeley, en la mayoría de los casos siempre haciendo hincapié en los aspectos materiales de la cultura.

A partir de la década de 1980, este enfoque geográfico logró pasar de lo morfológico a lo simbólico, es decir, se consiguió dejar de pensar en lo religioso como un elemento más del territorio, para ver el conjunto de simbolismos que las creencias religiosas impregnan y producen en la cohesión territorial, y los sistemas simbólicos que las sociedades traducen en la espacialidad.

\section{Luján como laboratorio de la dimensión espacial de lo religioso}

El interés de abordar la espacialidad religiosa en la ciudad de Luján se funda en su carácter de hierópolis (ROSENDHAL, 2009), ya que es una urbe donde lo religioso posee un papel totalmente relevante y opera como una dimensión central en la organización del espacio de la ciudad.

Es el centro de peregrinación católica de mayor importancia de la Argentina, que cada año recibe millones de visitantes (las cifras varían según la fuente).

El proceso de producción del espacio urbano de Luján y su consolidación como centro religioso gira en torno a ciertos discursos espaciales relacionados a la imagen de una Virgen, cuya "decisión de quedarse" fue la acción que comenzó a gestar el aglomerado en cuestión. El mayor cohesionador de la territorialidad lujanense está representado por el universo de lo religioso. Aunque también sus influencias abarcan planos que van más allá de la religiosidad y se desbordan hacia lo secular, considerando que ambas esferas no son dicotómicas sino complementarias.

Así, la ciudad se ha ido produciendo en tanto hierópolis, es decir, una urbe que muestra formas espaciales particulares vinculadas a su sacralidad: la esfera de lo sagrado posee un poder dominante por sobre los demás ámbitos; hay diferencias entre tiempo sagrado y tiempo común, y su territorialidad está marcada material y simbólicamente por un lugar sagrado que, además, posee un papel político trascendente (ROSENDHAL, 2009). 
En cuanto a la primera particularidad se podría esgrimir cómo el marco religioso envuelve entre tantas otras a la esfera económica, siendo el turismo en torno a las peregrinaciones y demás visitantes, uno de los principales generadores y motores de la economía local, que además denota un alto nivel de concentración.

El segundo punto se vincula con las temporalidades que se activan en este tipo de ciudades signadas por flujos peregrinos y otros visitantes. La temporalidad se modifica en función de todas estas formas de movilidad, sean religiosas o no, alterando los ritmos cotidianos de la ciudad.

La tercera cuestión queda cristalizada en la construcción de la Basílica Nacional, templo que territorialmente enmarca el sitio de mayor importancia y reunión de los devotos, estandarte de la mayor sacralidad. Esta obra arquitectónica es resultado de la materialización en el territorio de un proyecto socio-religioso-político llevado a cabo por el padre Salvaire desde fines del siglo XIX (MARQUIEGUI y BINETTI, 2005).

Por último, al respecto de la dimensión política, se podría mencionar que la construcción de un templo de semejante trascendencia debió contar con el aval del poder político y de un Estado que se estaba conformando, y que enlaza con toda una serie de dispositivos que operan en pos de sellar la alianza entre el estado argentino y la Iglesia Católica.

En un tiempo donde la conformación de la identidad del estado nacional estaba aún en camino y el flujo de inmigrantes que se recibía era notable, proyectar la elaboración de una Basílica y una patrona nacional, podría pensarse como un paso más para afirmar a la Argentina como una nación "Católica Apostólica Romana”. Pero, además, con cierta proyección regional al considerarse a la propia Virgen de Luján como patrona de Argentina, Paraguay y Uruguay, forjando su influencia a nivel regional.

\section{Un primer acercamiento a la ciudad}

A partir de los enfoques que propone el constructivismo geográfico empezamos a indagar sobre las maneras en que se construye cotidianamente la religiosidad de la ciudad de Luján y las disputas que se producen en el espacio público.

En una primera instancia (Flores y Giop, 2017), a modo de prueba piloto, se decidió concentrar el trabajo en lo que se define como "centro histórico" (un total de 83 manzanas) de la ciudad. 
Se priorizó concentrarse en el eje comercial de la ciudad, que, además, durante los fines de semana, debido a peregrinaciones, fiestas religiosas o simplemente por llegada un gran flujo de personas, los usos de esos espacios desbordan estas características y se ven solapadas por las prácticas turístico-religiosas. Por lo tanto, la elección del área se vinculó a que puede considerarse el sector de mayor flujo en toda la ciudad, ya sea en el tiempo de lo cotidiano como en la extraordinariedad de los tiempos de las peregrinaciones. La Basílica de Nuestra Señora de Luján, el Cabildo, la terminal de ómnibus, el Centro Cívico (Municipalidad de Luján y otras dependencias), los bancos y los comercios de mayor importancia se encuentran dentro de este denominado casco histórico.

Uno de los primeros interrogantes que surgieron fue precisamente qué criterio utilizar para ilustrar que el espacio está expresando alguna manifestación de religiosidad. Para esto, las ideas construidas por el geógrafo Claude Raffestin (1986) quién desarrolla el concepto de semiotización del espacio funcionó como salida. La categoría se refiere al proceso mediante el cual los grupos sociales y los sujetos le incorporan al espacio una semiósfera, es decir, un conjunto de signos culturales que caracterizan a una sociedad.

Joël Bonnemaison, otro geógrafo cultural, también construye una serie de ideas para el abordaje cultural del territorio del habitar (LEFEBVRE, 1972) y sus apropiaciones materiales y simbólicas. Cuando predomina la dimensión cultural, la espacialidad "puede engendrar un sentimiento de pertenencia que adquiere la forma de una relación de esencia afectiva e, incluso, amorosa con el territorio. En este caso se convierte en un ámbito de identidad o, si se prefiere, de identificación, y puede definirse como “una unidad de arraigo constitutiva de identidad”" (BONNEMAISON, 2004: 130). En efecto, el territorio es al mismo tiempo una realidad material y una realidad cultural. "El geosímbolo es un marcador espacial, un signo en el espacio que refleja y forja una identidad [...]. Los geosímbolos marcan el territorio con emblemas que arraigan las iconologías en los espacios-lugares. Delimitan el territorio, lo animan, le confieren sentido y lo estructuran" (BONNEMAISON en RAICHENBERG y HEAULAMBERT, 2008: 179). Siguiendo estas categorías, se puso el interés -exclusivamenteen los geosímbolos religiosos. 
Fue necesario realizar exhaustivas salidas a campo para recorrer la zona delimitada y poder comenzar con la tarea de registrar cada geosímbolo que se identificaba. A lo largo de más de seis meses se realizaron recorridos por la totalidad de las calles escogidas, muchas veces transitando los mismos lugares en reiteradas ocasiones.

Además de este recorrido peatonal basado en la observación fue muy importante la estrategia de entablar entrevistas desestructuradas o directamente charlas con los sujetos que transitan estos espacios. Como resalta Olsson (1978), los límites de la ecúmene de una persona están dados por sus límites en cuanto al lenguaje y los signos. Por los tanto, a través del lenguaje también se podría acceder a su ecúmene territorial. Esto nos llevó a identificar geosímbolos que, si bien a simple vista uno no podría resolverlos, con estos discursos territorializadores se pudieron concretar.

$\mathrm{Al}$ asistir al campo en sucesivas oportunidades emergió una multiplicidad de marcas religiosas con distintas localizaciones y sentidos; hecho que obligó a sistematizar la información siguiendo un orden taxonómico específico. 
De estas sistematizaciones se generaron diferentes cartografías de las cuales se decidió hacer una selección que sirva a modo ilustrativo de algunos de los alcances que se alcanzaron en esta etapa.

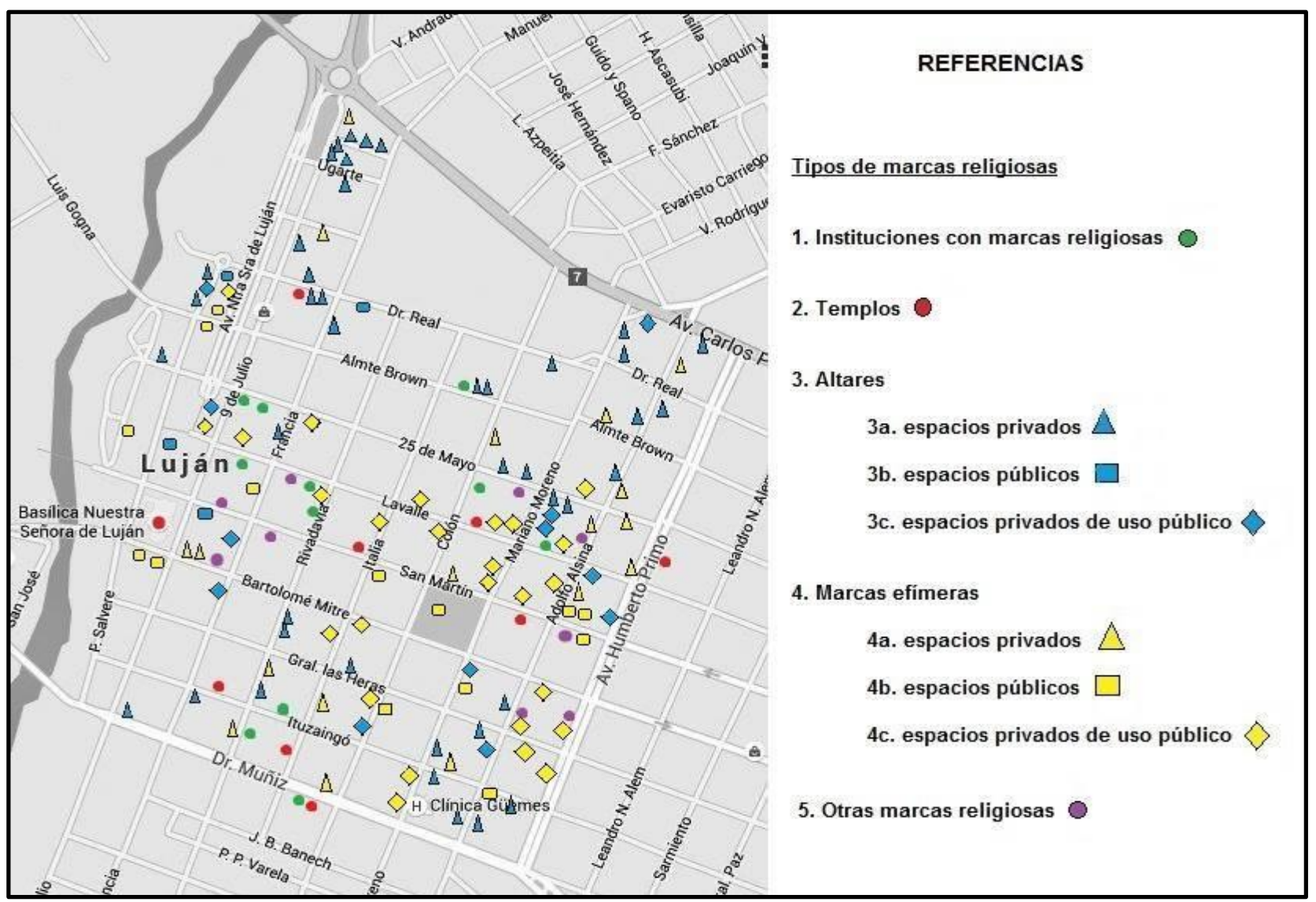

Figura 1. Mapa $\mathrm{N}^{\circ}$ 1. Clasificación de geosímbolos según tipo de marca religiosa.

Fuente: elaboración propia sobre la base de trabajo de campo sistematizado. Escala 1: 12000. 


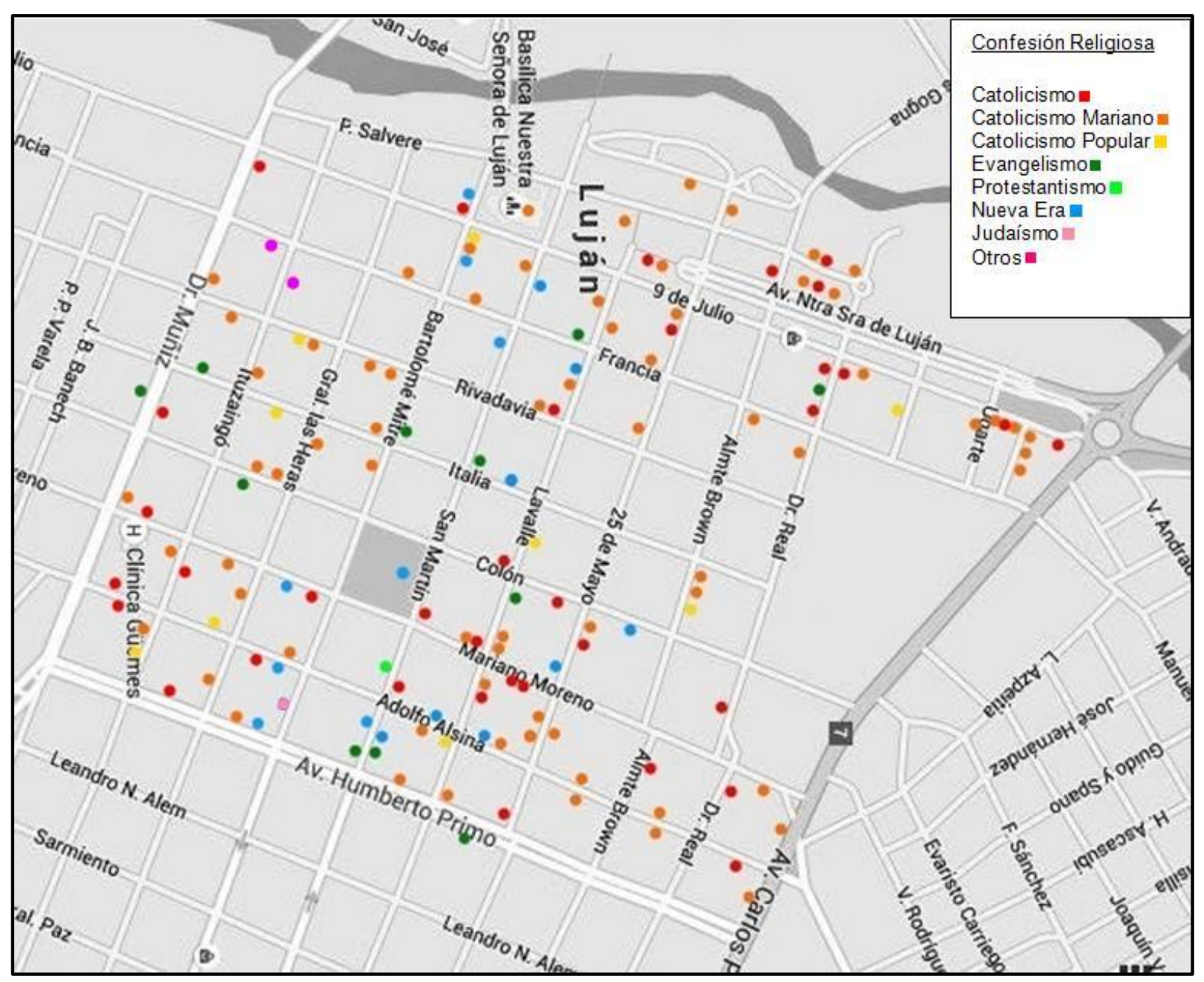

Figura 2. Mapa $\mathrm{N}^{\circ}$ 2. Clasificación de geosímbolos según confesión religiosa.

Fuente: elaboración propia sobre la base de trabajo de campo sistematizado. Escala 1: 12000.

\section{Los templos como geosímbolos espaciales}

La intención de ampliar el área de estudio más allá del casco histórico para abordar la totalidad de la ciudad de Luján siempre estuvo presente, aunque había conciencia de que el desafío de extender la investigación a dimensiones mucho más amplias no iba a ser fácil de enfrentar.

En una primera instancia se consideró la opción de llevar a cabo un muestreo criterioso y exhaustivo; sin embargo, las heterogeneidades internas de la ciudad constituían un escollo difícil de afrontar para generar resultados que fueran realmente representativos. Se debe tener en cuenta que cada barrio posee características propias que van desde su morfología espacial, los usos y representaciones de los sujetos- 
habitantes y las disímiles características que éstos poseen. La construcción de la territorialidad a partir de esos sujetos implicaría diferentes imaginarios urbanos (LINDÓN, 2007), prácticas y lógicas del habitar.

Otra opción que se barajó fue la de implementar exactamente la misma metodología que ya se había llevado a cabo. La ventaja de contar con todo el bagaje teórico ya trabajado, sumada a la experiencia construida en etapas anteriores parecían ser razones suficientes para elegir ese modus operandi. Sin embargo, por cuestiones de presupuesto, tiempo y disponibilidad de recursos humanos la tarea probablemente iba a resultar trunca.

No obstante, la problemática que se buscó resolver desde un orden que se podría considerar metodológico, finalmente se logró afrontar desde el ámbito de lo teórico. Se resolvió extender el área de estudio hacia toda la ciudad de Luján, pero en este caso concentrarse en una sola categoría de geosímbolos: los templos. Dentro de esta clasificación se propuso pensar a los templos, no desde concepciones clásicas, sino que, por el contrario, era necesario repensar de manera más amplia e inclusiva.

Para entender los complejos procesos que emergen a la hora de la construcción (material y simbólica) de un templo, parecen acertadas las palabras del geógrafo Roberto Lobato Correa (201 1). El brasileño entiende a la cultura como estructuras de significados y a la política como el medio por el cual estas estructuras se vuelven públicas. De esta manera, hay una lucha asimétrica entre diferentes poderes para codificar estos signos.

Esto posee un correlato totalmente geográfico que se logra conceptualizar a través de la categoría de formas simbólicas espaciales, las cuales resultan en la territorialización simbólica y material de diferentes posturas o discursos. Por eso mismo, el proceso de semiotización espacial no debe pensarse como armónico, constante o acabado.

Si pensamos el proceso de semiotización espacial, en términos de producción de templos, es necesario profundizar en este concepto.

Desde esta perspectiva, se conceptualiza como templo a cualquier sitio de permanencia más o menos estable, donde los sujetos desarrollan la práctica de un culto específico. No refiere necesariamente la construcción típica del cristianismo, la cual fue concebida y desarrollada morfológica y simbólicamente desde su origen como lugar exclusivamente vinculado al desarrollo de las prácticas religiosa. Esto abre el abanico a una cantidad de templos, los cuales incluyen sitios en los que un edificio se reutiliza y 
resignifica para pasar a activar otros usos no religiosos. Un ejemplo podría ser el caso del primer cine de Luján, llamado "Numancia". Este edificio supo por muchos años ser la única oferta de consumo en masa para películas dentro de los límites del partido. Sin embargo, desde el 2010, el inmueble fue adquirido por la iglesia neopentencostal CIA, la cual reconfiguró -sin dudas- la construcción (religiosa) de este lugar. Estos procesos, de resignificación de espacios anteriormente utilizados para otros fines culturales es abordado por Frigerio (2002) al respecto de la dimensión religiosa del espacio urbano.

Además, estas formas simbólicas espaciales, no tienen por qué tener una existencia que se manifieste únicamente desde su morfología, cuestión que puede ser abordada a través del estudio de las narrativas espaciales (LINDÓN, 2008) de los sujetos cotidianos que habitan estos espacios.

También a la hora de delimitar los templos se tuvo en cuenta lo que Flores (2018) denomina "la trampa de lo sagrado/profano". Este conjunto de ideas desarrollados por Mircea Eliade (1956) llevaban a comprender estos fenómenos desde una perspectiva totalmente binaria. Según Elíade existen espacios sagrados con un conjunto de características que lo separan de los demás, por lo tanto, considerados no sagrados, o profanos. Nótese la definición por oposición en sentido residual, es profano, porque no es sagrado; porque no tiene un conjunto de características que así lo definan. En palabras del filósofo: “...el espacio de lo sagrado crea heterogeneidad espacial, al contrario de la experiencia profana, para la cual el espacio es homogéneo y neutro" (ELIADE, 1956. p. 26).

En este caso Elíade utiliza la categoría de hierofanía como motor de la creación de un área apartada y demarcada del entorno que lo rodea, y que ejerce una fuerza que lo hace extraordinario y único (SANTOS, 2009). Si se utiliza este marco como delimitador, uno también corre el peligro de caer en categorizaciones esquemáticas. Por ello, la salida a "esa trampa" es justamente romper con la idea de que la sacralidad y la profanidad son características intrínsecas de los espacios, y entenderlas como texturas espaciales que se activan en determinados escenarios que los actores encienden en contextos particulares. En síntesis, un templo - en tanto geosímbolo - sería cualquier materialidad geográfica más o menos estable que, en determinados contextos (sean permanentes o pasajeros) posee estructura, usos y sentidos vinculados al desarrollo de alguna práctica religiosa o sagrada. 


\section{Un campo religioso desigual y regulado}

En Argentina, desde la reforma de la Constitución Nacional de 1994 se considera que el Gobierno Federal sostiene el culto Católico Apostólico Romano, colocando a esta institución en una situación de favoritismo religioso (FRIGERIO y WYNARCZYK, 2008). La ligazón entre el Estado nacional y esta institución es resultado de un largo proceso de construcción histórica, que por supuesto no estuvo exento de tensiones y negociaciones.

Benedettí (2011) al explicar lo que denomina enfoque del territorio políticocultural, sostiene que en todo proceso de territorialización a nivel estatal ocurren una serie de abstracciones, las cuales no necesariamente se manifiestan de forma lineal o en un orden explícito. La primera es la forma territorial, en la cual se evidencian procesos de construcción de límites físicos o simbólicos. Sigue, en segunda instancia, la forma simbólica en donde se elaboran elementos discursivos (desde nombres, toponimias, el proponer a la Virgen de Luján como protectora de la Nación), símbolos fijos (banderas, escudos, la Basílica de Luján en sí) y las prácticas sociales que los mantienen cohesionados (las peregrinaciones, por ejemplo). La tercera forma a la que hace referencia es la institucional, que va desde administraciones políticas, sistemas escolares y, al igual que la forma anterior, las prácticas que las mantienen hermanadas. Por último, habla de una estabilización, en el sentido que una vez establecidas las demás formas territoriales, esta última es necesaria para su extensión en el tiempo.

Consideramos evidente lo dificultosa que sería la tarea de querer desvincular históricamente al Estado argentino de la Iglesia Católica, y más aún la construcción de la Basílica de Luján como centro del catolicismo vernáculo (MARQUIEGUI y BINETTI, 2005).

Más allá de esta situación hay que resaltar que en la Argentina existe la libertad de culto religioso, aunque sujeta a cierto tipo de controles impuestos en un mercado religioso regulado.

En 1992, se constituyó el proyecto de ley conocido como "Proyecto Centeno", el cual fue enviado al Congreso por el Poder Ejecutivo Nacional y declaró los derechos de la libertad religiosa y de culto, que se encuentran íntimamente ligados a los de libertad de conciencia y de pensamiento, que sólo admiten para su limitación en su ejercicio y reglamentación que los mismos se exterioricen (GENTILE, 2003). 
Si bien esta libertad en cuanto a las decisiones en el ámbito religioso por parte del Estado argentino es efectiva, está atada a ciertas regulaciones de carácter administrativo y social que van cambiando.

A partir de 1976, como dispositivo de control social se exigió la inscripción a toda religión que no responda a la Iglesia Católica en un Fichero de Cultos, según la ley $\mathrm{N}^{\circ}$ 21.745. En la actualidad, con algunos cambios, pero estructuralmente con los mismos objetivos existe el Registro Nacional de Cultos (RNC) que depende de la Secretaría de Cultos.

Vale aclarar que también existe un Registro Provincial de Cultos en la provincia de Buenos Aires, el cual no se tuvo en cuenta para la presente instancia. ${ }^{2}$

De esta manera toda institución socio-religiosa obtiene una personería jurídica una vez que completa las demandas administrativas para quedar anotado.

Por otra parte, los cultos interesados en inscribirse en el registro pueden hacerlo gratuitamente, descargando los formularios disponibles de manera digital. Además, los postulantes deberán cumplir con usa serie mínima de requisitos. Entre ellos se encuentran: a) presentar la historia de la organización religiosa, que debe contener una descripción de la historia de la entidad religiosa desde su constitución y deberá estar firmada por la máxima autoridad religiosa; b) construir un conjunto de normas estatutarias de la entidad religiosa, de las que surja su finalidad específicamente religiosa, forma de gobierno y modo de designación de autoridades; c) elaborar las principales características de la doctrina, a través de un informe donde se exprese detalladamente la corriente religiosa a que pertenece, los principales fundamentos de su doctrina, las fuentes principales y los elementos distintivos del culto; d) dar cuenta de las actividades permanentes y regulares de culto; e) informar los ritos y ceremonias más importantes y si las actividades de culto contienen sacrificios de animales; f) periodicidad, horario y personas a cargo de las celebraciones; y g) formalizar los establecimientos escogidos y la currícula de estudios correspondiente para la formación de los ministros que ejerzan el culto.

La existencia de este Registro da cuenta de las desigualdades del campo religioso argentino, en donde las instituciones socio-religiosas deben moverse entre el favoritismo y la desigualdad. No solamente con respecto al culto católico (que no debe

\footnotetext{
${ }^{2} \mathrm{Al}$ respecto se recomienda consultar el texto de María Pilar García Bossio (2016). 
inscribirse y tiene su propia Secretaría), sino también entre aquellos que deciden inscribirse y las que no, y entre los que son más aceptados a nivel social o más estigmatizados en el plano de las prácticas y las creencias.

La existencia de este modelo de campo religioso y las particularidades de este Registro hacen que las situaciones que se presentan sean muy diversas y complejas.

En muchos casos, algunos cultos utilizaban este medio como una herramienta de institucionalización, legitimación y mitigación de las estigmatizaciones sociales. Si bien se podría pensar que el Registro se construyó como una medida de ejercer una regulación y armar una base de datos estatal de la cuestión religiosa, muchos grupos religiosos vieron esta alternativa como algo totalmente positivo, ya que al registrarse formalizaban su existencia ante el Estado y la comunidad. Otros grupos suponen que su existencia no necesita del reconocimiento del Estado, ni de ninguna otra entidad, y entonces funcionan al margen de estos registros, teniendo en cuenta en que su inscripción es voluntaria pero no obligatoria y que muchos de ellos no encajan en el modelo burocrático que exige este organismo.

\section{Mirar las periferias}

El Municipio de Luján cuenta, según el Censo Nacional de Población, Hogares y Vivienda 2010, con una población de 106.273 personas, que se concentran mayoritariamente en la ciudad homónima (78.346 habitantes). Los residentes de esta urbe, a su vez, se distribuyen desigualmente en 45 barrios muy dispares en cuanto a su morfología espacial, y en siete localidades de diferentes dimensiones (Jaúregui, Pueblo Nuevo, Carlos Keen, Olivera, Open Door, Torres y Cortínez).

Mediante la utilización de la base de datos disponible en el Registro Nacional de Cultos se procedió a la sistematización de una cartografía de las instituciones inscriptas de la ciudad de Luján y el resto del partido. Si bien el RNC, como ya se comentó, tiene ciertas limitaciones, no pareció una herramienta de gran poder y con un fuerte reconocimiento a nivel institucional muy válida para la etapa embrionaria en la que se encontraba la investigación. En el paso siguiente se cruzó metodologías de campo para conocer, de manera efectiva, si ese grupo inscripto se evidenció en el territorio a través de alguna materialidad geográfica que funcionara como templo. Del cruce de ambas instancias se pudo determinar que en todo el partido existen 35 cultos anotados: 
2 en Jáuregui, 1 en Olivera y el resto en la ciudad de Luján y sus barrios. Dentro de este universo hubo 3 casos que no se pudieron localizar en el territorio. Ante esta situación se procedió a elevar un pedido formal al Departamento de Catastro de la Municipalidad de Luján, entidad que respondió de manera muy colaborativa pero, a pesar de aportar su base de datos, se pudo corroborar que no existían dichas direcciones declaradas ante el RNC. Esto muestra un panorama de 32 cultos inscriptos que pudieron ser georeferenciados mediante el uso de herramientas digitales, especialmente el Google Maps (Figura 3, Mapa 3).

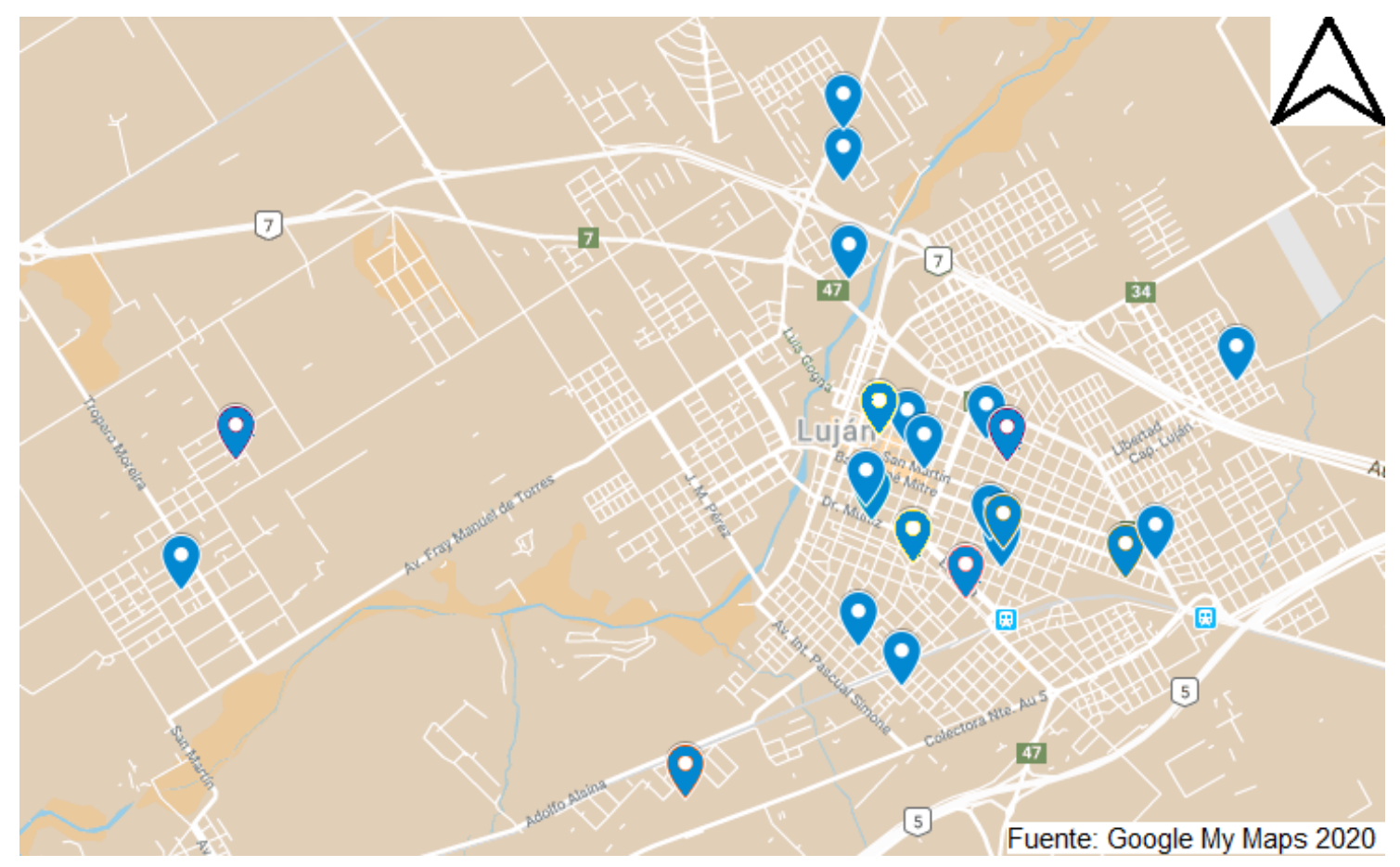

Figura 3. Mapa $\mathrm{N}^{\circ}$ 3. Templos inscriptos en el Registro Nacional de Cultos.

Fuente: elaboración propia. Escala 1: 150000

El siguiente paso fue mapear las instituciones sociorreligiosas y luego proceder a comprobar si realmente tenían una existencia territorial que pueda ser identificada a través de alguna materialidad geográfica o geosímbolo espacial.

Al realizar salidas a campo o utilizando diferentes programas de imágenes satelitales, 8 de ellos (por lo menos en la actualidad) no pudieron ser situadas. Incluso, se intentó dialogar con los habitantes de la zona, quienes se manifestaron de manera tal que no podían ubicar el potencial templo y no lo reconocían en su territorialidad 
cotidiana. Esta situación generó un nuevo mapeo que decantaba el realizado a priori con la base de datos del RNC, y que reducía las cifras a un total de 24 instituciones con existencia real.

El hecho de que estén inscriptas en el RNC pero no tengan una existencia en el territorio puede corresponderse con la idea anteriormente planteada. El registro fue utilizado en muchos casos como una herramienta de legitimación de los templos e instituciones no católicas. De esta manera, existe la posibilidad que realicen todos los trámites correspondientes para ser reconocidos por el Estado; sin embargo, sólo lo harían desde lo administrativo/burocrático. Además, hay que tener en cuenta que el formulario de inscripción sólo exige la declaración de un domicilio que no necesita ser corroborado; de hecho, en algunos casos, los encargados del trámite mencionan sus domicilios particulares. En otros casos puede tratarse de instituciones que fueron registradas, funcionaron un tiempo y luego dejaron de hacerlo, pero no dieron la baja en el padrón ministerial (Figura 4, Mapa 4).

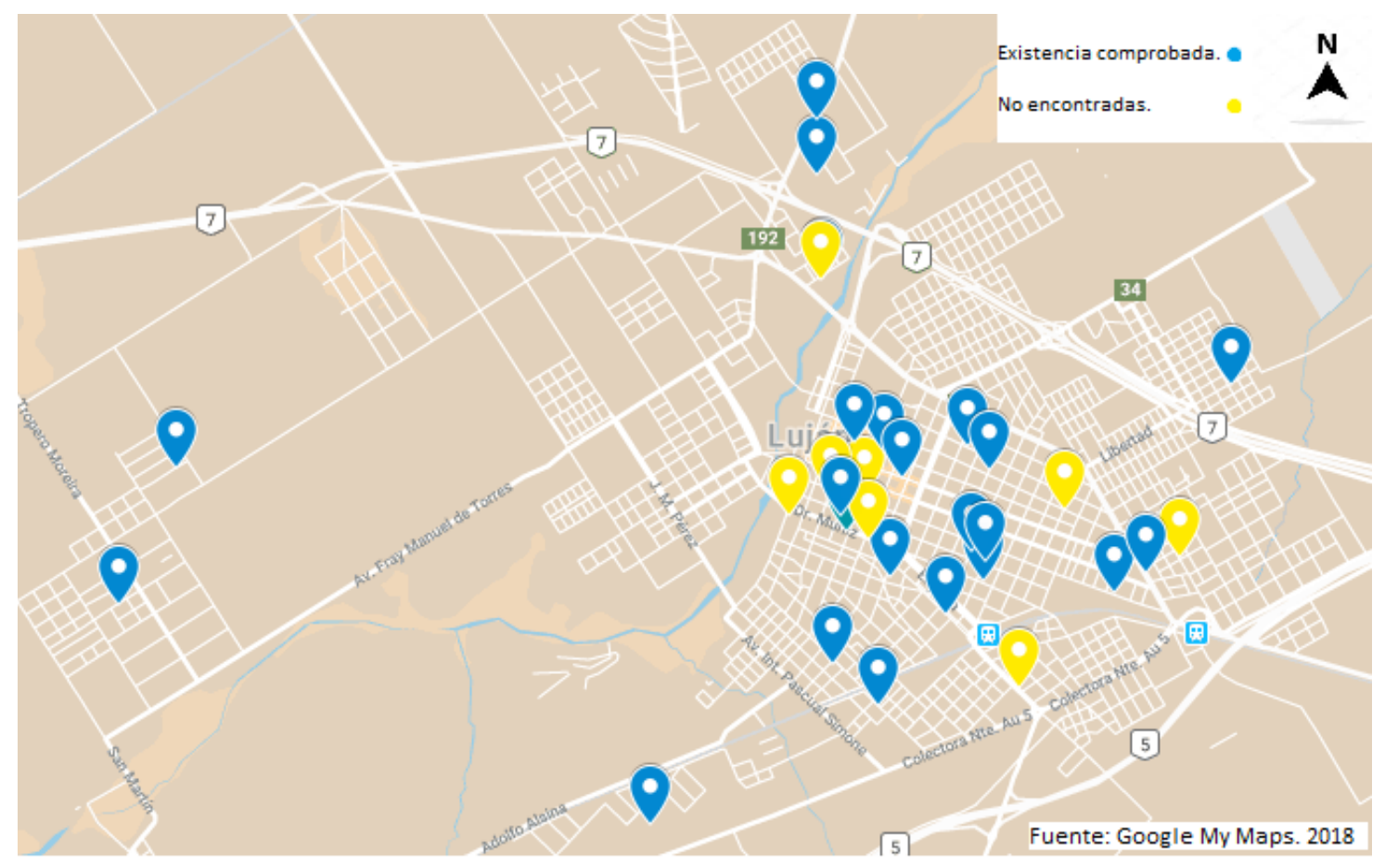

Figura 4. Mapa $\mathrm{N}^{\circ} 4$. Localización de templos comprobada.

Fuente: elaboración propia. Escala 1: 150000.

Luego de georeferenciar las instituciones religiosas y sus manifestaciones territoriales, se procedió a realizar una tipología para diferenciar pertenencias religiosas 
que expresaban los templos como geosímbolos. En este sentido era fundamental conocer las adscripciones porque daban cuenta de cómo se construía esa diversidad en las periferias de la ciudad a partir de la presencia de confesiones que se fueron instalando en el país (a nivel más macro) y en la ciudad (a nivel más micro) en distintos momentos históricos y coyunturas particulares, sobre todo traduciendo la idea que la instalación de templos no católicos en el centro de la ciudad se volvía dificultoso por el rol clave que tuvo la Basílica Nacional. Los resultados se expresan en el mapa 5 de la figura 5.

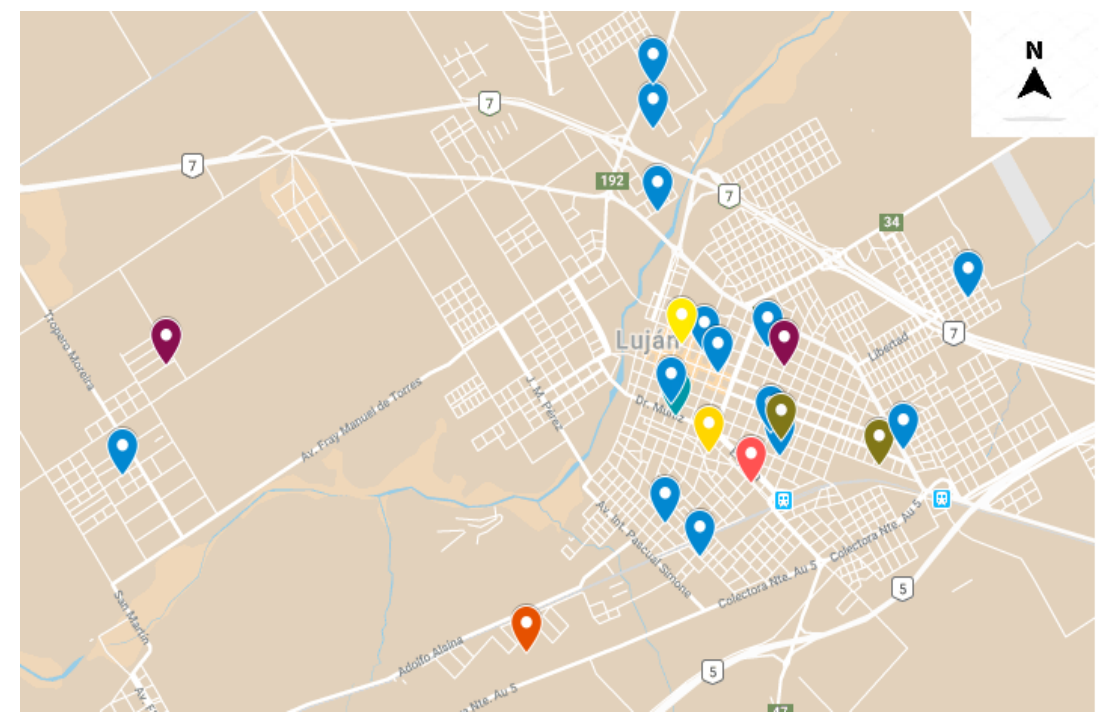

Templos por confesiones religiosas.

Neopentecostales. •

Testigos de Jehová. •

Espiritistas.

New Age. •

Africanistas. •

Iglesia de los Santos de los últimos días. •

Mapa $\mathrm{N}^{\circ} 5$. Templos según confesión religiosa.

Fuente: elaboración propia. Escala 1: 150000.

De un total de 24 instituciones señalizadas en el partido, la existencia de los neopentecostales con 15 templos es mayoritaria (más del 60\%). Esta tendencia ya se podía observar en la primera etapa de la investigación cuando se analizó la semiografía del centro. Si bien en la zona céntrica se agrupan la mayoría, su presencia en barrios periféricos y, dentro de éstos, algunos de niveles socioeconómicos bajos son muy considerable, incluso en localidades por fuera de la ciudad de Luján como Jáuregui. Esta categorización se identifica por una amplia heterogeneidad interna que engloba a los protestantismos tardíos dentro de un mismo universo, utilizando como principal variable la temporal: nos referimos a los movimientos muchas veces denominados "evangélicos" que arriban en etapas avanzadas del siglo XX. 
El segundo grupo con mayor presencia, aunque con una diferencia importante, es el de los Testigos de Jehová con 3 templos. No debería pasarse por alto su distribución en el partido, debido a que cuentan con una sede por localidad: una en Luján (ciudad), una en Jáuregui y otra en Olivera. Sin dudas es una estrategia que busca no yuxtaponerse en el territorio para también lograr una mayor influencia espacial.

Con dos casos cada una, los templos Espiritistas y New Age son los siguientes en cuanto a cantidad de presencia. En cuanto al primer grupo, la ubicación corresponde a zonas céntricas, siendo la más importante (y antigua) la Asociación Escuela Científico Basilio que ha mudado su sede en varias oportunidades; inclusive llegó a instalar dos sedes dentro de la ciudad. Los templos New Age se tratan de una categoría polisémica que acoge a un conjunto muy heterogéneo de prácticas, símbolos, imágenes y sistemas de creencias. Los dispositivos asociados a la llamada Nueva Era recrean prácticas de origen oriental y/o nativistas mezcladas con un fuerte contenido psicológico (VIOTTI, 2011). Si bien están dentro de la ciudad se ubican espacialmente en zonas residenciales alejadas de los ejes comerciales y turísticos.

Con una institución en el partido se presentaron dos casos: La Iglesia de los Santos de los Últimos Días, ubicada en la calle Avellaneda, que cuenta con una estructura edilicia que corresponde a una arquitectura homogeneizada que suelen presentar este tipo de movimientos. El templo o, más allá del espacio para llevar a cabo los rituales, cuenta con instalaciones para celebrar reuniones y actividades sociales más allá del ámbito religioso, tales como parques de deportes.

Por último, en el RNC existe un templo vinculado a religiones de matriz afro africanista. La institución IleAse Iya Mi Nana Ade Ui. Se encuentra ubicado en el Barrio San Antonio, que, si bien catastralmente corresponde a la localidad de Jáuregui, su historia espacial merece un análisis por separado

En sus orígenes este espacio se erigió como un barrio de sectores medios y altos que actualmente podría ser catalogado como neorrural. En la mayoría de los casos se presentaban movimientos pendulares de los habitantes debido a que gran cantidad de los propietarios no residían solo en Luján, sino que usaban las viviendas como "casas de finde semana” o de segundas residencias. La primera sede de la Universidad Nacional de Luján funcionó en terrenos ubicados en este barrio. En la actualidad esta lógica se modificó y existe una población que reside de manera permanente con una presencia mayoritaria de sectores medios. 


\section{A modo de cierre}

El desafío de extender el trabajo hacia la totalidad del partido parecía a priori de una complejidad metodológica significativa. La estructura y logística necesaria para llevar a cabo una tarea de semejante envergadura no parecía factible desde los recursos con los que se contaba. Sin embargo, por lo menos en este primer acercamiento hacia las periferias, se logró a través de modificaciones desde lo conceptual, una interesante variable. El hecho de repensar la categoría de geosímbolo (BONNEMAISON, 2004) para concentrarse en los templos fue de gran utilidad.

Además, correrse de concepciones más clásicas de lo que se comprende como templo también hizo posible llevar a cabo un trabajo con un perfil más amplio hacia la diversidad religiosa. Categorías como geosímbolo (BONNEIMASON, 2004) o formas simbólicas espaciales (CORREA, 2011) permitieron posicionarse por encima de lo que entendemos como un sesgo (muchas veces inconsciente) de estudiar a los fenómenos religiosos desde un prisma católico-céntrico. Esta situación no escapa a los templos, a los cuales muchas veces se los considera únicamente como estructuras altamente delimitadas, con permanencia estable y concebidas única y específicamente para fines sagrados.

En cuanto a lo metodológico, el cruce de diferentes fuentes como el Registro Nacional de Cultos, salidas a campo, encuentros y entrevistas con sujetos habitantes, Google Street View entre otras, si bien demandó una tarea exhaustiva fue otro pilar nodal del trabajo. Si entendemos que el espacio urbano se constituye cotidianamente con el accionar de cada sujeto habitante, "salir" al territorio sigue siendo una tarea básica para el quehacer geográfico, aunque no se debe restar importancia a la amplia gama de herramientas tecnológicas que, siendo utilizadas idóneamente, pueden enriquecer los resultados y llevar a razonamientos mucho más fructíferos.

Las conclusiones a las que se arribaron en esta segunda etapa, si bien fueron constructivas, terminaron abriendo nuevos interrogantes acerca de la espacialidad de los templos. Este momento de exploración nos abre nuevos caminos para repensar el trabajo geográfico y poder entender a las ciudades como un sistema en constante construcción, como contenedoras de disputas y trayectorias siempre con protagonismos de poderes totalmente asimétricos. 
El camino de pensar (y por qué no producir) a una sociedad y espacios cada vez más igualitarios, buscando una mayor pluralidad religiosa se vuelve compleja en un Estado tan cercano a la Iglesia Católica desde sus orígenes, por eso el trabajo no puede darse como cerrado. Un desafío más constituye ahondar en los casos particulares y su historia socio-territorial ya que nos puede sumar nuevas pistas sobre las estrategias de los grupos y sus decisiones a la hora de instalarse y permear en una hierópolis de características singulares.

\section{REFERENCIAS BIBLIOGRÁFICAS}

BAILLY, A. Lo imaginario espacial y la geografía: en defensa de la geografía de las representaciones. Anales de Geografia de la Universidad Complutense, 9, 11-19, 1989.

BENEDETTI, A. "Territorio: concepto integrador de la geografía contemporánea” en SOUTO, P. (Coord.) Territorio, lugar, paisaje. Prácticas y conceptos básicos en Geografía, Buenos Aires: Ed. FFyL de la UBA, 2011.

BONNEMAISON, J. La géographie culturelle, Ministère de l'éducation nationale, de l'enseignement supérieur et de la Recherche. Comité des travaux historiques et scientifiques (C.T.H.S.), $2^{\text {a }}$ Ed., Paris, 2004.

FERNANDEZ CHRISTLIEB, F. “La Geografía Cultural” En: LINDÓN, A. Y HIERNAUX, D. Tratado de Geografía Humana, Anthropos, México, 2006.

FLORES, Fabián. "Lo religioso y el espacio. Apuntes desde la Geografía" en CLOCLET DA SILVA, Ana y DI STEFANO, Roberto, História das Religiões: dimensões epistemológicas e teóricometodológicas, Rio de Janeiro: Prismas, 2018.

FLORES, F. y GIOP, M. "Geosímbolos religiosos en el espacio público. El centro de Luján como laboratorio de diversidad religiosa", Revistas Estudios Socioterritoriales, Tandil: Centro de Investigaciones Geográficas CIG, Instituto de Geografía, Historia y Ciencias Sociales IGEHCS, CONICET/UNCPBA, 2017.

FRIGERIO A. y WYNARCZYK H. "Diversidad no es lo mismo que pluralismo: cambios en el campo religioso argentino (1985-2000) y lucha de los evangélicos por sus derechos religiosos". En Sociedade e Estado, 23(2), Universidade de Brasília, 2018.

GENTILE, J. "Por qué una ley de libertad religiosa" en BOSCA, R. La libertad religiosa en la Argentina: aportes para una legislación. Buenos Aires: Calir / Konrad Adenauer Stiftung. LINDÓN, A. (2007) "Los imaginarios urbanos y el constructivismo geográfico: los hologramas espaciales". En Revista Eure, Vol. 23, Nº9, Pontificia Universidad Católica de Chile, Santiago de Chile, pp. 31-46, 2003.

"De las geografías constructivistas a las narrativas de vida espaciales como metodologías geográficas cualitativas". En, Revista da ANPEGE, Vol. 4, Porto Alegre, 2008, p. $7-26$.

LEFEBVRE, H. La vida cotidiana en el mundo moderno. Madrid: Alianza, 1972. 
CORRÊA, R, L. "Las formas simbólicas espaciales y la política”. En, ZUSMAN, P.; HAESBAERT, R.; CASTRO, H. y ADAMO, S. (eds.) Geografías culturales. Aproximaciones, intersecciones y desafíos. Editorial de la Facultad de Filosofía y Letras de la UBA, 2011.

FRIGERIO, A. "Outside the Nation, outside the Diaspora: Accommodating Race and Religion in Argentina”. Sociology of Religion, 63(3), p. 291-315, 2002.

GARCÍA BOSSIO, P. "Estado y religión en el espacio institucional: el caso de la Dirección provincial de culto de la provincia de Buenos Aires". En: WYNARCZYK, H.; TADVALD, M. (organizadores) Religião e política ao sul da América Latina, Porto Alegre: CirKula, 2016.

MARQUIEGUI, D. y BINETTI, J. “Lapides clamabunt (las piedras hablarán): el debate sobre la construcción de la Basílica de Nuestra Señora de Luján. Trabajo presentado ante el Grupo de Estudios de Historia de la Iglesia, Instituto Ravignani, Facultad de Filosofía y Letras de la Universidad de Buenos Aires, 2005.

ELÍADE, M. The sacred and the profane. Nueva York: Brace and World Inc, 1956.

SANTOS, M, P. "Religión y dinámica espacial. Del espacio y de los lugares sagrados al territorio religioso”. En CARBALLO, C. (Coord.), Cultura, territorios y prácticas religiosas, Buenos Aires: Prometeo, 2009.

OLSSON, G. "Of ambiguity or far cries from a memorializing". In: LEY, D. \& SAMUELS, M. (eds.) Humanistic geography: Prospects and problems. London: Croom- Helm, p.109-120, 1978.

RAFFESTIN, C. Écogénèse territoriale et territorialité” en AURIAC Y BRUNET (Dir.), Espaces, jeux et enjeux. París, Fayard, 1986.

RAICHENBERG, E. y Heau-Lambert, K. «Por una sociología histórica de los espacios periféricos de la Nación en América latina”. Antípoda, (7), (julio-diciembre), 2008.

ROSENDAHL, Z. Hierópolis: Lo sagrado y lo urbano, Rio de Janeiro: UERJ, 2009.

UNWIN, T. El lugar de la geografía, Cátedra, Madrid, 1992.

VIOTTI, N. "Notas sobre socialidad y jerarquización en la nueva religiosidad de los sectores medios urbanos". En: Papeles de trabajo, 5 (8). Revista electrónica del Instituto de Altos Estudios Sociales de la Universidad Nacional de General San Martín. Buenos Aires, 2011. 